\section{Sensemaking of Financial Institution Actors in the Adoption and Elaboration of Integrated Reporting}

\author{
Simone Leticia Raimundini Sanches ${ }^{1}$ \\ Kelli Juliane Favato' \\ Evelise Slewinski ${ }^{1}$ \\ Marguit Neumann ${ }^{1}$ \\ ${ }^{1}$ State University of Maringá (UEM), Postgraduate \\ Program in Accounting (PCO), Maringá, Brazil
}

Recebimento:

$11 / 26 / 2018$

Aprovaçáo:

$11 / 06 / 2019$

Editor responsável:

Profa. Dra. Natalia Vidal

Avaliado pelo sistema:

Double Blind Review

\begin{abstract}
Purpose -To analyze the sensemaking (Weick, 1995) of the actors involved in the adoption and elaboration of Integrated Reporting in a Brazilian financial institution (Itaú Unibanco S.A.).

Design/methodology/approach - Exploratory and interpretative case study, with semi-structured interviews with nine actors who compose the Working Group for elaborating Integrated Reporting, alongside documental analysis. The data were analyzed using the content analysis technique.
\end{abstract}

Findings - Sensemaking applied to Integrated Reporting is an interpretative process involving its elements (business models, capitals, material themes, value creation), it promotes organizational change by means of disruptive actions, and it is adaptive when it adjusts to organizational culture.

Originality/value - The study contributes to the discussion of the adoption of Integrated Reporting at the enterprise studied, at the Brazilian Commission for the Follow-up of Integrated Reporting, at the International Integrated Reporting Council, at Brazilian consultancy firms, and among users of the report. The study also contributes to the literature relating to this theme.

Keywords - Integrated Reporting. Integrated Thinking. Sensemaking. Bank. Brazil.

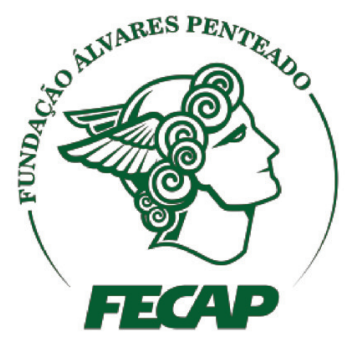

Revista Brasileira de Gestáo de Negócios

DOI: $10.7819 /$ rbgn.v22i3.4067 


\section{Introduction}

Adopting and preparing an Integrated Report (IR) as a corporate document for communicating value generation to stakeholders in the short, medium, and long terms (Burke \& Clark, 2016; Mio, Marco, \& Pauluzzo, 2016) requires organizational changes, such as transitioning from sector-based teams to multisector teams, and changes in business vision (Kistruck \& Beamish, 2010). These organizational adjustments occur because integrated thinking among the actors involved is a requirement for the development of IRs (Higgins, Stubbs, \& Love, 2014; Lodhia, 2015).

Concerning the actors involved, Bommel (2014), Jensen and Berg (2012), and Stubbs and Higgins (2014) stress the importance of observing the reasons that lead companies to voluntarily adopt integrated reporting, the authors' insights, the mechanisms they use, and whether organizational change is taking place. Higgins et al. (2014) identified that as sustainability values have been incorporated into the culture of organizations, individuals have changed along with them, because signification and perception processes are continuous and interwoven.

Perego, Kennedy, and Whiteman (2016) point out that studies on integrated reporting emphasize the structure and concepts of the framework established by the International Integrated Reporting Council (IIRC), as well as the content of the report, but do not investigate the individuals involved in integrated reporting. This gap highlighted by Perego et al. (2016) has been confirmed in Brazilian studies (Abreu, Zaro, Luiz, Bellen, \& Vicente, 2016; Freitas \& Freire, 2017; Ricardo, Sabrina, \& Bortonlon, 2017) as well as international ones (Clayton \& Rogerson, 2015; Fasan \& Mio , 2017; García-Sanchez \& Noguera-Gámez, 2017; Rensburg \& Botha, 2014), which all explore the content, structure, or concepts of the IIRC framework for integrated reporting, or of disclosed IRs.
When investigating individuals involved in integrated reporting, one possible approach is sensemaking (Daft \& Weick, 2005; Weick, 1973; Weick, 1995) - the creation of senses and meanings by the actors (individuals) regarding an object in a given context. In this study, we understand that sensemaking refers to the actors' actions with regards to producing and reproducing senses and meanings concerning the IR and, consequently, promoting organizational changes for the adoption and preparation of that report in the organization.

Therefore, the question that guides this study is: How does the sensemaking of the actors involved in the process of adopting and preparing an IR occur? The objective is to analyze the sensemaking (Weick, 1995) of the actors involved in the adoption and preparation of IRs at a Brazilian financial institution (Itaú Unibanco S.A.). This is an interpretive exploratory case study, based on the content analysis of semistructured interviews held between the months of November and December 2015.

This case was chosen because the adoption of integrated reporting was internal, conducted exclusively by a specific team - the Working Group (WG) - which is interesting for studying the actors involved and sensemaking. For McNally, Cerbone, and Maroun (2017), when it comes to preparing IRs, trusting thirdparty consultants can reduce the involvement of those who implement and disseminate the principles of this reporting.

The main result of this investigation evidences that sensemaking in IR adoption and preparation, in this case study, is based on identifying and interpreting ideas, which, when they create sense for an actor, and the latter shares them with other actors (or sectors), constitute an interpretive process regarding what an IR and its elements (business model, capital, material topics, value generation) are. The sensemaking resulting from integrated reporting brings about organizational changes through disruptive actions. It is also adaptive when it fits the elements of organizational culture. 
The results of this study can contribute to the investigated organization itself and to organizations interested in adopting integrated reporting, including consulting firms, as well as to the IIRC and to the Brazilian Commission for Monitoring Integrated Reporting [Comissão Brasileira para Acompanhamento do Relato Integrado (CBARI)] when it comes to discussions around IR adoption.

The practical implication is that sensemaking is a critical factor for an organization that intends to adopt integrated reporting. Neglecting this critical factor can be a determinant when it comes to understanding, accepting, and disseminating this practice. It involves stakeholders as well, as it allows them to understand that IRs are a social idea internally built in the organization that issues them; therefore, the analysis of the informational content of said reports will be unique for each company.

This study advances the integrated reporting literature by exploring the actors involved, but also points out the need to continue research from this perspective, involving the actors at the different stages of IR adoption in domestic or international organizations. Moreover, it complements the literature with a focus on the IIRC framework and its content.

\section{Sensemaking and Integrated Reporting}

The understanding involved between generating and disseminating information is a process pertaining to an object or phenomenon in a certain context (Heijden \& Cramer, 2017). For Weick (1973), processes are interconnected individual behaviors. Thus, informational behavior is related to the understanding and processing of information in the organizational environment; to the individual's subjectivity in obtaining, processing, and sending information; and to the influence of managers when creating strategies to pass on information (Daft \& Weick,
2005) in order to meet the informational needs of users.

The proposal of IRs is to integrate financial and non-financial information, showing the relationship between the organization's strategy, governance, and financial, environmental, social, and economic performance (Stubbs \& Higgins, 2015). This relationship includes the business model and all performance dimensions, for long-term value creation (Burke \& Clark, 2016). Considering these elements, we understand that adopting and preparing an IR involves changes in the informational behavior of the organization, and the actors giving a new meaning to their activities.

Sensemaking emphasizes the way in which actors make sense of the object or phenomenon they interpret in a context (Daft \& Weick. 2005; Weick, 1973; Weick, 1995), it promotes critical thinking (Guiette \& Vandenbempt, 2017), and it captures elements in the subjective process of formal and informal interactions, asymmetries of knowledge, experience, and collaborative motivations (Heijden \& Cramer, 2017). Our understanding of IR-applied sensemaking is that it is a continuous process involving the systemic organization of financial and non-financial information through the scanning (Weick, 1995) of information from different sectors in a company. To do so, the actor interprets the information obtained and propagates the realization of an action (integrated thinking and IR preparation). As this action is propagated, the perception and interpretation of the information contained in the IR is changed, creating new senses or meanings. This feeds back the actor's interpretation cyclically. Thus, each IR is unique and dynamic in its presentation and structure, and coherent with the organization's business model.

For Weick (1995), sensemaking is a process based on seven properties (Table 1), which are interactive and have interrelated implications. 
Table 1

Sensemaking Properties

\begin{tabular}{|c|c|}
\hline $\begin{array}{l}\text { Grounded in Identity } \\
\text { Construction }\end{array}$ & $\begin{array}{l}\text { Process of defining the 'self' and the 'collective self' through interaction with actors. Interaction allows } \\
\text { the identity to be continuously reconstructed, so there may be some ambiguity between sensemakers, as } \\
\text { they are at different (re)construction stages. }\end{array}$ \\
\hline Retrospective & $\begin{array}{l}\text { Sensemaking occurs in the present time, but comes from past experiences. It is a reflexive act that } \\
\text { depends on values deemed important in the current perception. }\end{array}$ \\
\hline $\begin{array}{l}\text { Enactive of Sensible } \\
\text { Environments }\end{array}$ & $\begin{array}{l}\text { Organizational actors build their own environment by means of stimuli and restrictions resulting from } \\
\text { interactions. The organizational environment changes over time. }\end{array}$ \\
\hline Social & $\begin{array}{l}\text { Collective process, inherent in social interactions, carried out by a social construction of discourse. The } \\
\text { construction of meanings or senses is a social and shared process. }\end{array}$ \\
\hline Ongoing & $\begin{array}{l}\text { The actors participate in the events, given the continuous flow of activities they join, and (re)acting, } \\
\text { creating order, and making sense is inevitable. }\end{array}$ \\
\hline $\begin{array}{l}\text { Focused on and by } \\
\text { Extracted Cues }\end{array}$ & $\begin{array}{l}\text { Cues are fragments or structures of simple or known languages by which people attribute a broader sense } \\
\text { of what may be happening, and ideas can be connected in networks of meaning. }\end{array}$ \\
\hline $\begin{array}{l}\text { Driven by Plausibility } \\
\text { rather than Accuracy }\end{array}$ & $\begin{array}{l}\text { One does not seek an absolute truth; one seeks a continuous and dynamic truth of a narrative, making } \\
\text { it comprehensible. It prioritizes reasonability (acceptable among individuals, a minimum of consensual } \\
\text { information) over accuracy. }\end{array}$ \\
\hline
\end{tabular}

Note. Source: Adapted from “Sensemaking in Organizations," by K. E. Weick (1995). Thousand Oaks: Sage.

Considering that these sensemaking properties are the fundamental elements for the actors to disseminate integrated thinking and IRs in any organization, we suggest correlating the properties in a final version (Table 2). These properties are based on IIRC Framework 1.0 and on the literature on integrated reporting (Bommel, 2014; Higgins et al, 2014; Jensen \& Berg, 2012; Lodhia, 2015; Perego et al., 2016; Stubbs \& Higgins, 2014).

Table 2

\section{Sensemaking properties in IR adoption and preparation process}

\begin{tabular}{ll}
\hline Identity Construction & Business model, what we think and what we do. \\
\hline Retrospective Experience & Analyze the past to understand the organization and support its sustainability. \\
\hline $\begin{array}{l}\text { Environment under } \\
\text { Construction }\end{array}$ & Integrated-thinking development. \\
\hline Collectivity & The actors' collectivity in the construction of the company's identity. \\
\hline Continuity & Integration of information and capitals to create value. \\
\hline Web of Ideas & Ideas can be connected in networks of meaning for the business model. \\
\hline Plausibility & Guiding principles (such as materiality, conciseness, reliability) for the information contained in the IR. \\
\hline
\end{tabular}

These properties were analyzed in the case study and they suggest that individual sensemaking, when shared and integrated, generates collective sensemaking (Choo, 2003; Daft \& Weick, 2005; Ivanova-Gongne \& Törnroos, 2017; Sheng, 2017; Zilber, 2002). Therefore, an IR is not a department-exclusive document, but rather a report that depicts what the organization and its sustainability are.

\section{Methodological Procedures}

This research involves a single, exploratory, and interpretive case study (Bryman, 2012; Chua, 1986; Kistruck \& Beamish, 2010; Myers, 2013) 
conducted at Itaú Unibanco. Data were collected from semi-structured interviews held in loco between November and December 2015. The interview script (Appendix B) was prepared based on Appendix A and Lodhia (2015).
The interviewees were selected (Table 3) by snowball sampling, meeting the requirement that they must be involved in IR adoption and preparation at the institution. The 2013, 2014, and 2015 IRs complemented the interview data.

Table 3

\section{Interview structure}

\begin{tabular}{cl}
\hline Interviewee & Position \\
\hline I1 & Senior finance analyst \\
I2 & Coordinator within the sector of disclosure management and financial controls \\
I3 & Finance analyst \\
I4 & Institutional communication manager \\
I5 & Accounting consolidation coordinator \\
I6 & Accounting disclosure analyst \\
I7 & Internal controls manager \\
I8 & Manager within the sector of disclosure management and financial controls \\
I9 & Audit committee member \\
\hline Recording time: $\mathbf{1 3 h 3 0 m i n}$ \\
\hline
\end{tabular}

We analyzed the interviews using the content analysis technique (Bardin, 2016) because we interpreted the meaning the actors (the interviewees, our unit of analysis) gave to the IR. After transcribing the interviews, we performed a pre-analysis - that is, we skimmed this material, preparing it for exploration. We started exploring the transcribed interviews by organizing the paragraphs according to the interviewees' statements (context unit).

Afterwards, we coded the paragraphs of each interview according to the IR-applied sensemaking properties (Appendix A). With that done, we grouped the context units by code and found that we had reached data saturation. We interpreted the coded reports with the aid of the Atlas*TI software, version 8 , and noticed that the properties initially proposed should be adjusted (Table 2). The interpretation was validated by the institution in a presentation at a CBARI meeting, in March 2017.

\section{Sensemaking of IR actors}

In this section, we present the results from the analysis of the interviews with the actors involved in integrated reporting at Itaú Unibanco. We begin with a brief context that elucidates how integrated reporting has become a practice at the institution.

The initial contact with the concept of Integrated Reporting occurred between 2011 and 2012, through an Accounting Disclosure and Analysis Management employee who was studying at a higher education institution, and through the Sustainability department, which took part in the Rio+20 conference, according to I1 and I4. I4 adds that other sectors, such as Investor Relations and Corporate Communication, besides being engaged in the preparation of the Consolidated Annual Report (CAR), meet the demand of shareholders, stakeholders, and investment funds that request information on the institution's environmental performance.

Up until then, there were four different reports [...] it made more sense to produce a single report [...] they were written in different phases, so you end up requesting the same information at different times, and this information was sometimes inconsistent (I1). 
Different reports are sources of ambiguity and informational noise, as well as rework. Some employees realized that integrated reporting was a corporate communication strategy and noted that it was being adopted by European financial institutions.

In South Africa, companies must disclose their IRs to join the stock market. This was something we started to bring in and try to engage our directors with, attentive to the fact that the theme would be important in the future (I1).

In the same period, a new CEO, who also knew about the IIRC and IRs, gave top-down institutional support, but

There was some resistance at the beginning [...] I know that he (the CEO) would speak to our superintendent \# and the subject would die there, but he (the CEO) persevered, continued insisting, until one day \# went to Frankfurt for one of these IIRC meetings [...] participated in the event, understood the proposal better, and then when he came back to Brazil, he came back with a different attitude [...] I think we have something to work with. (I2)

Then, "he (the CEO) was one of the people who said 'no, let's do this' and he gave carte blanche and started to engage people from above" (I1). Thus, the first version was released in 2014 (referring to financial year 2013) and considered the "year of integrated report presentation, as proposed by the International Integrated Reporting Council” (Itaú, 2013, p. 3).

To prepare this IR, Itaú Unibanco created a WG, composed of analysts from the four sectors (Finance, Sustainability, Investor Relations, and Corporate Communication), who had had the initial contact with this report. During 2013, the WG studied IR concepts and discussed the CAR.

This journey, according to interviewees I1 and I4, converges with the institutional vision:
To be the leading bank in sustainable performance, generating shared value for employees, customers, shareholders, and society, ensuring the longevity of the business and customer satisfaction.

As well as with the institutional values:

It's only good for us if it's good for the client; (ii) We're passionate about performance; (iii) People mean everything to us; (iv) The best argument is the one that matters; (v) Simple. Always; (vi) We think and act like owners; (vii) Ethics are non-negotiable.

We understand that the "sustainable performance," "shared value," and "business longevity" expressions, present in the institutional vision, and value (ii), are the institution's strategic elements associated with IR adoption. In addition, there are the actors who introduced the integrated reporting and those who resisted it, but then accepted it (understood the meaning) and, collectively, disseminated this reporting practice.

\section{I IR-Applied Sensemaking Properties}

Considering the context presented, we analyzed the sensemaking of the actors involved in integrated reporting at the institution, based on the suggested properties (Table 2). In said analysis, we confirmed that the properties are interactive and interrelated, as according to Weick (1995).

\section{I.I Identity Construction: Business model, What We Think and What We Do}

The "be the best bank, not the largest" motto was mentioned by the interviewees in the context of what the business is. "Largest is different from best, and I prefer to be the best rather than being the largest" (I2). Analyzing the sense of this motto, we observe that the institution's identity lies in aligning its financial objective with its social role by means of organizational practices that create value. 
Of course the bank's core is financial activity, so it creates financial value more than it creates any other type of value, but the bank has been seeking to create a very strong social value (I1).

We have a spiral of sustainable performance [...].

[...] the closer Itau is to society, investors, clients, the government [...] the more it creates value (I3).

This converges with the organizational vision; it mirrors what the business model is. The individual knowing their identity (selfknowledge) leads to the organization building, identifying, and sharing their sensemaking (Weick, 1995). We understand that the actors involved in integrated reporting strive to minimize ambiguities, but the employees at branches and service outlets may not realize what it means to 'be the best' and 'to generate shared value' (see property 3). Furthermore, we understand that 'being the best' and 'generating shared value' is aimed at stakeholders, at communicating with them about the institution's economic, financial, social, and environmental sustainability.

\section{[...] aware that the report is a process of continuous evolution, we always hope to provide relevant information to our stakeholders (Integrated Report 2014, p. 2).}

Bearing this in mind, we understand that, potentially, there is some ambiguity in the organizational identity due to the actors being at different stages of sensemaking (Weick, 1995). We also noticed differences in the stage of sensemaking when the sector-based view in the form of silos was changed for the IR to be prepared, since not all of the actors involved were aligned as to the understanding of the concepts and practices of this report (see properties 3 and 4).

Reflection on organizational identity involves the company identifying what it thinks and how it does so (Weick, 1995). This implies that changing a trajectory requires disruptive action (changing the culture and way of working, understanding one's job in the organization). In this case, integrating ideas and obtaining the product (IR) called for changes in internal practices to better communicate the business model (identity).

\subsubsection{Retrospective Experience: Analyze the Past to Understand the Organization and Support its Sustainability}

We observed that sensemaking involves the actors' perception that the organization's status quo results from their journey. In other words, what they are today stems from the past, just as the events or actions that take place in the present will have future effects. However, in the time lapse between change and/or adaptation of organizational practices and perception of results, we have the actors' expectations.

Oh, I'll show my CAR, do you want more? (I3)

[...] so that was complex, because we had no input to guarantee that the IR would bring benefits to the bank (I1).

Regarding this, we understand that the institution's experiences (journey) with voluntary corporate reports, such as the Global Reporting Initiative (GRI) since 2001, for disclosure of environmental and social matters, were experiences that favored the preparation of the CAR and IR. Other experiences - initial public offerings, participation in the New Market of the Brazilian Stock Exchange (B3), relationship actions (through meetings held by the Capital Market Investment Analysts and Professionals Association [Associação dos Analistas e Profissionais de Investimento do Mercado de Capitais (APIMEC)] - provided input for the institution to interpret its environment and legitimize its structure, mainly for the generation and communication of 
internal and external information, aligning with the business model (identity).

This edition of the Integrated Report introduces some structural changes when compared to the previous one. These changes are the result of our search for innovation, integration, and transparency in communicating with our stakeholders (Itaú Unibanco, 2014, p. 2).

We understand that the creation of meaning for IR adoption is the result of past experiences (GRI) in reporting information on sustainability, without associating financial and non-financial information. By adopting integrated reporting, the proposal is to associate information and its relationship with capitals (financial, manufactured, intellectual, human, social and relational, and natural). This suggests that the comprehension of an environment is a continuous organizational construction (Weick, 1995) (property 3).

\section{I.3 Environment under Construction: Development of Integrated-Thinking}

The act of preparing an IR allows communication between sectors that have never talked to each other (I9).

It is really complicated to take all of the bank's business fronts and shape them in the framework model, in that sense it was very complicated too (I3).

These statements express the WG's concern about preparing the IR, which internally required synergy and collectivity (property 4) in the communication flow among the actors involved. For this reason, the interviewees mentioned the 2013 IR as the first exercise of integrated communication. In other words, it is a developing activity in constant integration so that individual meanings become collective.
[...] we started to see the importance that the Dow Jones index has globally (I3).

We started to identify some points that supported our decisions (I1).

During the interviews and in their analysis, we noticed that the expression 'people' does not refer to a specific department, but to the organization as a whole. It is a discourse not of the individual (or sector), but a collective discourse (of the sectors involved in integrated reporting), denoting the integration of ideas, a basis for integrated thinking. Consequently, in a movement to overcome disconnected information or partitioned reports, the sectors started to make sense of the connectivity between them.

$I R$ is much more about changing culture than about publishing a report. [...] a change of culture changes the reports, changes the work, changes a lot of things (I1).

That said, we observed that IR adoption and preparation influenced the institution's internal environment, mainly the WG's behavior and culture, and the informational process for this report. This change in the internal environment is a consequence of the analysis of identity (property 1 ), journey (property 2), and collectivity (property 4).

We also evolved in the presentation of our business model, which now includes our risk factors, resource allocation strategies, results, and main challenges (Integrated Report 2014, p. 2).

Identity construction (property 1) as well as integrated thinking and information development occur through the WG's inputs for IR preparation. This is confirmed in the 2015 Integrated Report (p. 1): "We have presented the capital exposure to our material topics. We have identified the audiences most affected by each material topic. [...] We have improved interactivity by adding links to all presented icons." 
We understand that integrated thinking and reporting are interwoven processes of knowledge construction, of learning by doing collectively. This process results in the IR, a unique product with each edition in terms of its structure, as it is not a standardized document, and in terms of its content, due to the effort to communicate the integration between capital, material topics, and value generation.

However, if the integrated thinking and integrated information being developed in the institution have meaning created only for those involved in IR preparation, the potential benefits will be the connectivity of information for unification of reports and presentation of the sustainability of the business model, and for a specific audience (investors and shareholders). This, nonetheless, does not fully comprehend collectivity (property 4), that is, integrated thinking disseminated among employees working at branches and service outlets in Brazil and abroad (21 countries), who have direct contact with commercial customers. We note that it is a challenge for the bank to spread the concept and practice of integrated thinking to meet the organizational vision of "customer satisfaction" and institutional values (i) and (iii).

\section{I.4 Collectivity: The Actors' Collectivity in the Construction of the Organization's Identity}

For Weick (1973), the thinking of the actor and social functioning are essential for the acceptance of new concepts or models in the organization. Adopting integrated thinking at Itaú required the interaction of several sectors, as mentioned by I1: "We did not have this habit of one area directly working with another." The WG performed this interaction, concurrently with the implementation of the CAR.

The initial interaction between individuals was followed by interaction between sectors, sometimes with some resistance.

\section{[...] we see that people tend, they don't want} to understand... They want to show good things only, but that's not what the Report is about, you have to show the reality, if it's good, if it's bad... So the marketing staff are still a little concerned about that [...] (I6).

Another example of resistance, according to the interviews, was the concern from the Internal Control sector about the reliability and assurance of non-auditable, usually non-financial information disclosed in the IR. The institution needed to improve and adapt internal controls, but "companies may be evolving in the theme (IR) way faster than how audit firms are evolving" (I2). The interviewees reported that Price (the audit firm) is familiar with IR principles; only the 2015 IR was reviewed by independent auditors, who issued a limited assurance report.

We noticed that the interviewees' efforts towards disruptive actions prioritize consensus as a means for reaching collectivity: "Until we reach a consensus in all sectors, we don't make a final decision" (I3). For the interviewees, internal consensus is evidence that there is a collective meaning for a given IT subject (capitals, materiality, indicators, for instance). This is necessary because not all actors are at the same moment of meaning construction (comprehension of IR concepts): "I don't know the name of the capitals... Is it... Human capital... What is it called? Human, technical?" (I9).

This happens because while some actors in the WG, especially I1 and I4, bring the signals from the external environment to the IR, other actors receive those signals, with some impressions (meanings). Therefore, the internalization of IR concepts or practices is expected to be subject to ambiguities until a consensus is reached.

From the social interactions identified in this study, we understand that to create meaning for integrated reporting, individuals in the organization need to interact with each other, overcoming paradigms in order to reach a consensus, and to interact with other organizations, such as forums, the IIRC, the CBARI, and academic conferences. This forms 
meaning-sharing networks, developed gradually (property 5) and at different stages in relation to how close to or how far from the WG the actors are.

\section{I.5 Continuity: Integration of Information and Capital for Value Creation}

The creation of value, its sharing, and its longevity rely on the institutional vision stated by the bank. Based on the interviews and on the 2015 IR, we understand that they are seeking to integrate material topics (property 7) and capitals with their governance model, and the latter with the external environment.

[...] we assessed all material topics, individually, and identified, mainly, the need to integrate the "Socio-Environmental Risk" theme with the "Risk and Capital Management" theme, aligning our management with BACEN normative guidance no 4,327 (Integrated Report 2015, p. 45).

We'd talk about which theme was most impacting each capital. So, credit was classified as financial capital. Why? Why is it financial capital? Not necessarily, it is also social capital. Without the customer, there is no credit, but it impacts financial capital more (I1).

[...] we have this material on capital, and we do exercise after exercise, identifying all functions, everything the bank does, and trying to match everything with capital (I6).

The emphasis given in the 2015 IR to the integration of information on socio-environmental risk and risk and capital management is due to the fact that the aforementioned norm, from 2014 , refers to the implementation of the socioenvironmental responsibility policy of financial institutions. In other words, it refers to the socioenvironmental risks of activities and operations - therefore, of the value created, which may be positive, negative, or null. For instance, when granting credit to clients for them to invest, which socio-environmental risks can this investment generate? Following this reasoning, the lender becomes co-responsible for the risk and for the value created.

We are kind of trying to walk this path of how our operations influence the local economy (I1).

It is a process of mapping the path of value creation. This process is about integration of information and capital, of capital and material topics (what the bank judges important) and value creation. Regarding this,

We need to improve information connections [...] our next step is to measure that (I1).

We're trying to evolve in that. We can't just say "financial capital is this, natural capital is that, manufactured capital is this" (I5).

Evolution occurs by holding WG meetings, weekly or biweekly, to improve and discuss concepts of the framework and receive feedback, according to I1.

After the IR is released, together with the Standardized Financial Statements (SFS), in April, meetings to discuss the current year's IR process begin. This meeting frequency shows us that the 'collectivity' and 'continuity' properties interact so that the 'environment under construction' property can be developed. This interrelation of properties evidences that sensemaking is an uninterrupted process of scanning (Weick, 2005) information and minimizing ambiguities, thus bringing about new meanings and organizational changes.

\section{I.6 Web of Ideas: Ideas Can be Connected into Networks of Meaning for the Business Model}

Information scanning allows signs or cues to be captured from the internal and/or external 
environment, which form a sense for the actor and lead them towards learning. At the organizational level, this process is extended to the group of actors who form the collectivity (property 4), developing an interpretive organization (Daft $\&$ Weick, 2005).

In our analysis, we identified the CAR as a cue for IR adoption, as a sign that the institution perceived the need to present complete information, along with the GRI, for reporting environmental and social aspects of a financial institution. Another cue was the participation of employees in events on sustainable development and business sustainability, enabling the perception that integrated reporting "is a global trend" (I5). Teaching and research centers are disseminators of leads as well.

The convergence of these elements led to an action, a practice: to implement integrated reporting in the institution, according to a brief context presented at the beginning of section 4 . For this practice to be consolidated, new evidence must appear, and continuously (property 5). For instance, "few investors are directly concerned about this, here in Brazil. After disclosure, we were able to notice great interest from foreign investors" (I1).

We understand that cues can be simple mechanisms, out of which people in the organization make sense. That is, small leads in the process can connect to a subject (e.g., materiality, relevance, connectivity, value creation), forming networks of meanings (property 7 ) accepted by the collective. However, the speed at which cues become ideas and are attributed sense for an action varies from organization to organization.

\section{I.7 Plausibility: Guiding Principles for Information Contained in the IR}

Plausibility comprehends the search for a continuous, understandable, reasonable, and dynamic truth. The 2013, 2014, and 2015 IRs rely on the IIRC's guiding principles and on the institution's internal mechanisms.

We adopted the IR Banking Network guidelines. (...) This report was approved by our Governance bodies responsible, and reviewed by our independent auditors, who issued the limited assurance report on the 2015 integrated report (Integrated Report, 2015, p. 1).

The financial information presented in this report complies with the international financial reporting standards (IFRS), issued by the International Accounting Standard Board (IASB). The data relating to the segments, in turn, comprise managerial information not processed in accordance with the IFRS. These numbers and data are identified as "Managerial Data" (Integrated Report 2014, p. 3).

We always publish (the CAR and IR) on the same date, all to facilitate this assurance process for both [...] (I1).

We noticed that the bank does not want accurate information, but reliability through internal assurance (in 2013 and 2014) and external assurance, in 2015, when independent auditors issued a technical document on limited assurance. We stress that internal assurance was a concern of the WG as well as of the Internal Control department.

Another example of plausibility was the definition of material topics. This process started in 2014, with the definition of material topics in social, environmental, economic, and corporate governance terms. In 2015, the bank developed and validated the materiality matrix, combining material topics with capitals and related audiences (Figure 1). 


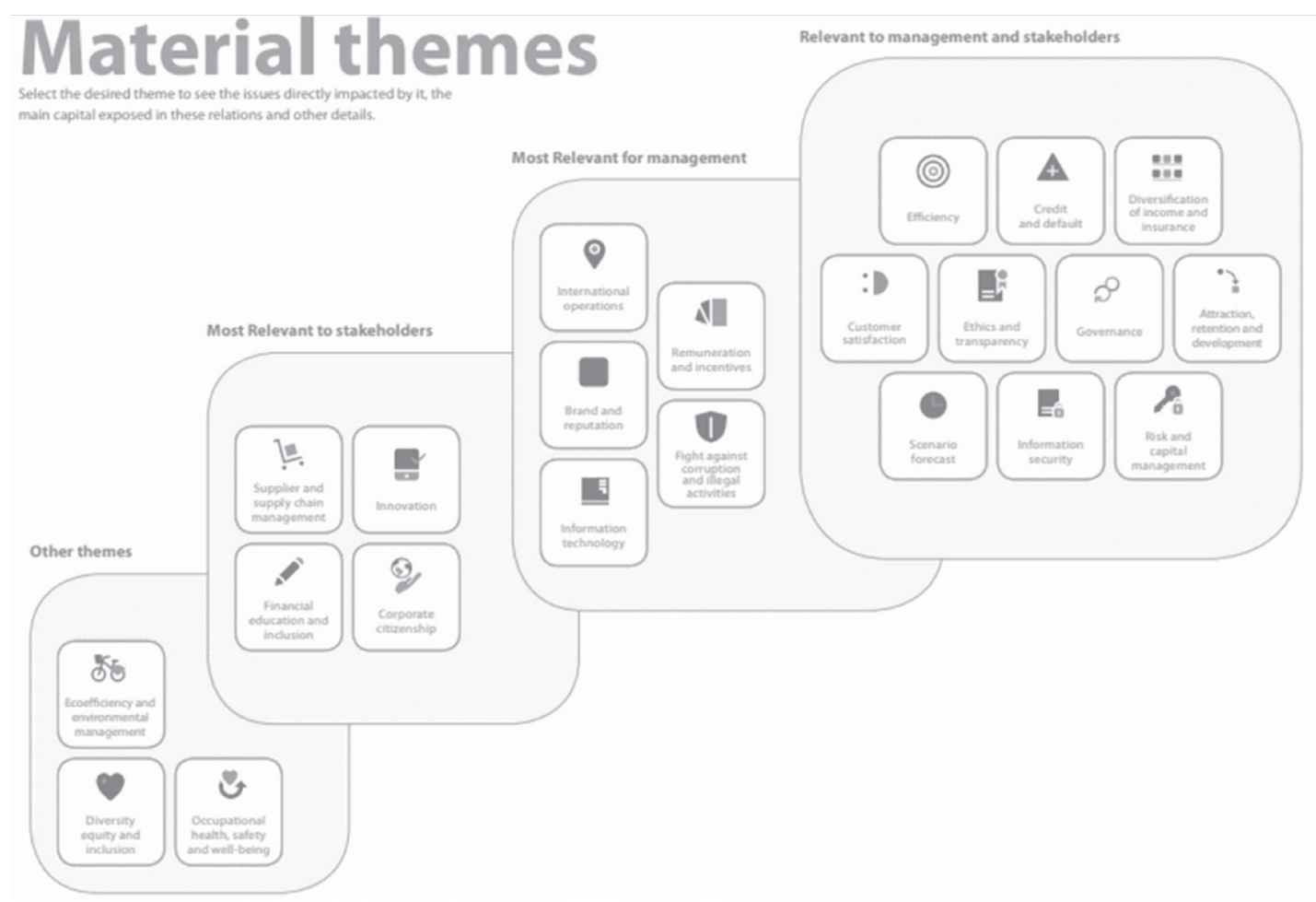

Figure 1. Materiality Matrix Integrated Report 2015.

Note. Source: Taken from “2015 Integrated Report,” by Itaú Unibanco 2015 (p. 46).

The materiality matrix is a narrative on what is relevant and for whom it is relevant. We understand that changes in the matrix call for revisions in the approach and connectivity of information, with interpolation with continuity (property 5). We also observed that the concept of materiality (or material topics), during the period in which the interviews were held, was under construction (property 3), but there was enough for disclosure. This confirms that the plausibility of integrated reporting involves being unique and dynamic each year.

\section{Discussion of Results}

Our discussion of the results is organized around the following aspects: reasons that led the bank to adopt the IR, and the mechanisms used; the organizational changes (disruptive actions) that have (not) occurred, including integrated thinking and reporting; the sensemaking developed.

We can state that Itaú's motivations in adopting the IR derived from a set of cues coming from the external environment into the internal environment of the organization, as reported in the context of section 4, and in property 6 - Web of Ideas. Among the cues, we highlight: the participation of employees in events on sustainability; signals being captured from the market; the fact that integrated reporting is a global trend in terms of communication of the value generated by organizations, although the Latin American scenario is volatile, and political systems are unstable (Ogliastri \& Zúńiga, 2016), causing concern about the business lying about financial-economic information; and the influence of teaching and research centers, which disseminate contemporary themes, besides training and supplying professionals to implement these themes in organizations. The inclusion of contemporary themes in organizational practices indicates an interest in informing stakeholders about actions and behaviors that signal how perennial the business and its positive and negative externalities are (Harrison, Freeman, \& Abreu, 
2015). Another external cue that has continued since 2013 was the institution's participation in the IIRC and CBARI, through announcements and the presentation of IR business cases.

It is worth mentioning that these sources of ideas (cues) formed a web, that is, a group of actors who have developed sensemaking for integrated reporting and become multipliers. Based on that, we highlight the role of disseminator actors in persisting when they encountered resistance from other actors, being the link between the external environment in search of evidence (scanning) and the internal environment in spreading concepts, promoting and managing organizational changes, and (re)building the business identity.

These aspects corroborate with Choo (2003), Daft and Weick (2005), and Weick (1983, 1995), who address the process of creating meaning and carrying out actions that start in the individual and reach the collective. And they explore what Bommel (2014), Jensen and Berg (2012), and Stubbs and Higgins (2014) point out as gaps in integrated reporting studies. Also, regarding the gaps that this study explores, we identified that the mechanisms used were scanning, the formation and performance of the WG for integrated reporting, the institutional vision of sustainable and shared performance, and the support given by the CEO (top-down action) that legitimized isolated initiatives and the free circulation of ideas through different hierarchical levels. This legitimacy was possibly the main mechanism for others to occur.

Organizational changes are aspects that Bommel (2014), Kistruck and Beamish (2010), Jensen and Berg (2012), and Stubbs and Higgins (2014) point out as likely to occur when an organizational practice is changed, including when it comes to communicating information (Daft \& Weick, 2005). One of the purposes of the IR is to communicate the value generated to stakeholders (Burke \& Clark, 2016; Mio et al., 2016). Sometimes, changing means (re)learning.

That said, the adoption of integrated reporting at Itaú initially promoted learning, as the people involved did not have knowledge about aspects related to the extension of integrated reporting concepts; about whether the latter were applicable to the banking sector; about what could be the benefits of the reporting model to stakeholders; about what benefits could be generated internally with the preparation of said model; and about how the IR differed from the CAR and GRI. This learning led the WG individuals to an organizational, incremental change, moving from sector-based teams to multi-sector teams, which enabled changes in the understanding of the business model (Kistruck $\&$ Beamish, 2010) and in informational behavior (Daft \& Weick, 2005) .

Based on the results of section 4, we observed a paradigm shift concerning the purpose of the actors in the accounting and financial sector. These actors realized that discussing and reporting non-financial information (information on human, intellectual, manufactured, natural and social, and relationship capital) is not exclusive to the Sustainability department, for instance, and that accounting is not just an information provider. The opposite is also true: the Sustainability sector is not limited to reporting non-financial information, given that such information is interwoven. This change corroborates with Higgins et al. (2014) and Stubbs \& Higgins (2014).

Integrated thinking and reporting stems from this. Bommel (2014) and Spence (2007) suggest that the IR, by requiring integrated thinking and reporting, shows how (non) sustainable a company's business model is in the long run. We understand that the longevity of a business model is not measured by quantitative aspects only, but rather it is integrated with qualitative aspects. That is because qualitative aspects encompass changes in behavior and processes that, indirectly, imply quantitative changes (improvements in performance through better resource usage, for instance).

Regarding this, we note that the interviewees identified that there were four different reports to meet the informational demand from the external environment. This set of reports generates rework, as well as ambiguity and informational noise, and shows how rethinking informational behavior calls for changes in qualitative information. 
Regarding integrated thinking and reporting, we further highlight the WG meetings, which lead employees to a collective and shared thinking, creating and establishing senses for their sectors and among sectors, as addressed in section 4. This involves the actors, in terms of their knowledge of the institution (their identity) and recognizing their capabilities, limitations, and challenges. We note the following as limitations and challenges at Itaú: disseminating integrated thinking beyond the WG, covering other sectors, branches included, since they are the ones that interact directly with customers, market the institution's financial services and products, and can have socio-environmental effects; not making the IR an informational marketing piece; and consolidating the materiality matrix, correlating the values generated between capitals, as well as aspects spanning socioenvironmental responsibility, and financial and ethical education, mainly in practices involving bank loans and spread.

To develop integrated thinking and prepare the IR, the WG actors used the experience of other reports (CAR and GRI), based on the culture of existing internal processes, incorporating into this culture the concepts of integrated thinking and reporting. Lodhia (2015) also reported these strategies in IR implementation at Goodbank in Australia. We observed no fundamental changes in the institution's cultural and political systems. This confirms Higgins et al. (2014), who consider that the first IRs are a combination of the processes that are being institutionalized in the organization. However, we could see an incremental change in the expansion of the WG, as a result of the dissemination of integrated thinking sensemaking, promoting interactions between the sectors of the WG members. For Guiette and Vandenbempt (2017), interactions lead to reflexivity during sensemaking, which inhibits practitioners from becoming stagnant and promotes emancipation from the idea of organizational and informational silos.

We understand that the changes were incremental at Itaú, in the sense of meeting an informational need that the institution had been developing: the CAR. In other words, the business model did not change, but up until the moment of this research, the actors involved in the informational process had changed, with said process going from sector-based (unidimensional) to multidimensional (holistic), enabling a greater consensus and better judgment as regards to the reflection of the work developed in each sector for the institution's activities. The accounting sector can be referred to as an example, which has become more inclusive in aspects such as socioenvironmental ones, no longer being a mere data provider.

With respect to the sensemaking developed at the institution, we understand that it is at an early stage. Fundamental concepts must have meaning created collectively, since the individual sense predominates in the WG. The IRs prepared and disseminated are being enhanced as a consequence of this sensemaking from the individual to the collective level. However, Daft and Weick (2005) and Weick (1983, 1995) mention that sensemaking is a continuous, uninterrupted, evolutionary, and interactive process.

We agree with these authors and observed this throughout the analysis presented in section 4, when we discussed the properties of sensemaking as regards to integrated reporting. In other words, and based on the research data, sensemaking properties are not sequential, but interrelated, so much so that we started this discussion with property 6 , because it refers to the context of how integrated reporting was implemented at the institution.

\section{Conclusion}

The objective of this research was to analyze the sensemaking (Weick, 1995) of the actors involved in IR adoption and preparation at a Brazilian financial institution (Itaú Unibanco S.A.). The sensemaking perspective allowed for an exploration of the interpretations and meanings attributed by the actors involved.

We conclude that sensemaking is a process interwoven, firstly, with the actor, and which, secondly, interweaves the latter with the organizational context. The two levels are 
indissociable and non-concurrent; that is, sensemaking starts with the individual, but its effect is perceptible when it reaches the collective. The fact that the individual and the collective can be at different stages of sensemaking implies its non-concurrence.

This interim involves an ambiguity of knowledge, interpretation, and meanings that adjust over time and for a certain period of time. For this reason, sensemaking is dynamic and results from a subjective process of formal and informal interactions. In other words, the senses made are not stable or adjustable over time. As an example, the properties of sensemaking oriented toward IRs, as analyzed in section 4, were adjusted, as mentioned in section 3. Therefore, the findings are limited to the institution studied, suggesting the need for further research using the properties analyzed.

We started this research by questioning how the sensemaking of the actors involved in the process of adopting and preparing integrated reporting occurs. Based on the results found, it seems that the sensemaking process of adopting and preparing an IR is driven by the WG, which is composed of sectors not used to working as a team, and was legitimized by the institution's executives. From this we infer that in situations in which the IR is implemented with an external or mixed team, the intraorganizational motricity may be different from that of the case studied, since the involvement of third parties requires acceptance from employees, increasing the resistance to integrated thinking and reporting. It is worth noting that there was resistance despite the team being internal.

As a suggestion for future research, studies could be replicated involving the interpretation process in an analysis of the dissemination mechanisms that have been implemented in integrated reporting. Critical and ethnographic research would also contribute to studying the actors involved in integrated reporting.

\section{References}

Abreu, A. C. S., Zaro, E. S., Luiz G., Bellen H. M., \& Vicente, E. F.R. (2016). Governança corporativa na estrutura conceitual do relato integrado: Divulgações das empresas brasileiras participantes do projeto piloto. Revista de Gestão, Finanças e Contabilidade 6(2), 31-49.

Bardin, L. (2016). Análise de conteúdo (L. A. Reto \& A. Pinheiro, Trad.). Lisboa: Ediçôes 70.

Bommel, K. V. (2014). Towards a legitimate compromise? An exploration of Integrated Reporting in the Netherlands. Accounting, Auditing \& Accountability Journal, 27(7), doi: 1157-1189. https://doi.org/10.1108/AAAJ-042013-1309.

Bryman, A. (2012). Social research methods (4a ed.). New York: Oxford University Press.

Burke, J. J., \& Clark, C. E. (2016). The business case for integrated reporting: Insights from leading practitioners, regulators, and academics. Business Horizons, 59(3), 273-283. doi: http:// dx.doi.org/10.1016/j.bushor.2016.01.001.

Choo, C. W. (2003). A organizaçāo do conhecimento: Como as organizaçôes usam a informaçâo para criar significado, construir conhecimento e tomar decisóes (E. Rocha, Trad.). São Paulo: Editora Senac São Paulo.

Chua, W. F. (1986). Radical developments in accounting thought. The Accounting Review, 61(4), 601-632. Retrieved from http://www.jstor. org/stable/247360

Clayton, A. F., Rogerson, J. M., \& Rampedi, I. (2015). Integrated reporting vs. sustainability reporting for corporate responsibility in South Africa. Bulletin of Geography, 29(29), 7-17.

Daft, R. L., \& Weick, K. E. (2005). Por um modelo de organização concebido como sistema interpretativo. Revista de Administração de Empresas, 45(4), 73-86. Retrieved from http:// bibliotecadigital.fgv.br/ojs/index.php/rae/article/ download/37304/36069 
Fasan, M., \& Mio, C. (2017). Fostering stakeholder engagement: The role of materiality disclosure in integrated reporting. Business Strategy and the Environment, 26(3), 288-305.

Freitas, B. F. G., \& Freire, F. S. (2017). Relato Integrado: Um estudo da aderência da estrutura conceitual proposta pelo IIRC no Relatório Socioambiental do Conselho Federal de Contabilidade. Sociedade, Contabilidade e Gestão, 12(1), 77-92.

García-Sanchez, I.-M., \& Noguera-Gámez, L. (2017). Integrated reporting and stakeholder engagement: The effect on information asymmetry. Corporate Social Responsibility and Environmental Management, 24(5), 395-413.

Guiette, A., \& Vandenbempt, K. (2017). Change managerialism and micro-processes of sensemaking during change implementation. Scandinavian Journal of Management, 33(2), 65-81. Retrieved from https://doi.org/10.1016/j. scaman.2017.02.002

Harrison, J. S., Freeman, R. E., \& Abreu, M. C. S. (2015). Stakeholder theory as an ethical approach to effective management: Applying the theory to multiple contexts. Review Business Management, 17(55), 858-869. doi: https://doi.org/10.7819/ rbgn.v17i55.2647

Heijden, A. Van Der, \& Cramer, J. M. (2017). Change agents and sustainable supply chain collaboration: A longitudinal study in the Dutch pig farming sector from a sensemaking perspective. Journal of Cleaner Production, 166, 967-987. doi: 10.1108/AAAJ-04-2013-1303

Higgins, C., Stubbs, W., \& Love, T. (2014). Walking the talk: Organisational narratives of integrated reporting. Accounting, Auditing \& Accountability Journal, 27(7), 1090-1119. doi: https://doi.org/10.1108/AAAJ-04-2013-1303

Itaú Unibanco (2013). Integrated Report 2013. Retrieved from https://www.itau.com.
br/_arquivosestaticos/RAO/PDF/EN/Itau-relatointegrado-ing.pdf

Itaú Unibanco (2014). Integrated Report 2014. Retrieved from https://www.itau.com.br/_ arquivosestaticos/RAO/PDF/EN/Integrated_ Report_2014.pdf

Itaú Unibanco (2015). Integrated Report 2015. Retrieved from https://www.itau.com.br/_ arquivosestaticos/RI/pdf/en/Integrated_Report_2015. pdf

Ivanova-Gongne, M., \& Törnroos, J. (2017). Understanding cultural sensemaking of business interaction: A research model. Scandinavian Journal of Management, 33(2), 102-112. doi: https://doi.org/10.1016/j.scaman.2017.04.001

Jensen, J. C., \& Berg, N. (2012). Determinants of traditional sustainability reporting versus Integrated Reporting. An institutionalist approach Strategy Environ. 21(5), 299-316.

Kistruck, G. M., \& Beamish, P. W. (2010). The interplay of form, structure, and embeddedness in social intrapreneurship. Entrepreneurship Theory and Practice, 34(4), 735-761. doi: https://doi. org/10.1111/j.1540-6520.201.00371.x

Lodhia, S. (2015). Exploring the transition to integrated reporting through a practice lens: An australian customer owned bank perspective. Journal of Business EthicsBus Ethics, 129(3), 585-598.doi: https://doi.org/10.1007/s10551014-2194-8

McNally, M. A., Cerbone, D., \& Maroun, W. (2017), Exploring the challenges of preparing an integrated report. Meditari Accountancy Research, 25(4), 481-504.

Mio, C., Marco, F., \& Pauluzzo, R. (2016). Internal application of IR principles: Generali's internal integrated reporting. Journal of Cleaner Production, 139, 204-218. doi: https://doi.org/ http://dx.doi.org/10.1016/j.jclepro.2016.07.149 
Myers, M. D. (2013). Qualitative research in business \& management (2nd ed). Croydon: SAGE Publications Ltd.

Ogliastri, E., \&Zúñiga, R. (2016). An introduction to mindfulness and sensemaking by highly reliable organizations in Latin America. Journal of Business Research, 69(10), 4429-4434. doi: https://doi. org/10.1016/j.jbusres.2016.03.008

Perego, P., Kennedy, S., \& Whiteman, G. (2016). A lot of icing but little cake? Taking integrated reporting forward. Journal of Cleaner Production, 136, 53-64. doi: https://doi.org/http://dx.doi. org/10.1016/j.jclepro.2016.01.106

Rensburg, R., \& Botha, E. (2014). Public Relations review is integrated reporting the silver bullet of financial communication? A stakeholder perspective from south Africa. Public Relations Review, 4O(2), 144-152.

Ricardo, V. S., Barcelo, S. S., \& Bortolon, P. M. (2017). Relatório de sustentabilidade ou relato integrado das empresas listadas na BM\&FBovespa: Fatores determinantes de divulgação. Revista de Gestão Social e Ambiental 11(1), 90-104. doi: https://doi.org/10.24857/rgsa.v11i1.1233

Sheng, M. L. (2017). A dynamic capabilitiesbased framework of organizational sensemaking through combinative capabilities towards exploratory and exploitative product innovation in turbulent environments. Industrial Marketing Management, 65, 28-38. doi: https://doi. org/10.1016/j.indmarman.2017.06.001

Spence, C. (2007). Social and environmental reporting and hegemonic discourse. Accounting, Auditing \& Accountability Journal, 20(6), 855-882. doi: ttps://doi. org/10.1108/09513570710830272.

Stubbs, W., \& Higgins, C. (2014). Integrated Reporting and internal mechanisms of change. Accounting, Auditing \& Accountability Journal, 27(7), 1068-1089. doi: https://doi.org/10.1108/ AAAJ-03-2013-1279

Stubbs, W., \& Higgins, C. (2015). Stakeholders' perspectives on the role of regulatory reform in integrated reporting. Journal of Business Ethics, 147(3), 489-508. doi: https://doi.org/10.1007/ s10551-015-2954-0

Weick, K. E. (1973). A psicologia social da organização (D. M. Leite, Trad.) São Paulo: USP.

Weick, K. E. (1995). Sensemaking in Organizations. Thousand Oaks: Sage.

Zilber, T. B. (2002). Institutionalization as an interplay between action, meanings, and actors: The case of a rape crisis center in Israel. The Academy of Management Journal, 45(1), 234-254. 


\section{Appendice A - Properties for empirical identification of sensemaking elements}

\begin{tabular}{|l|l|}
\hline Elementos & Propriedades do estudo \\
\hline Identity construction & $\begin{array}{l}\text { Propertied 1: The process of adopting and preparing the IR is based on the construction of the } \\
\text { organization identity as to what it "thinks and does". }\end{array}$ \\
\hline Retrospective experience & $\begin{array}{l}\text { Propertied 2: The process of adopting and preparing the IR uses retrospective experiences to understand an } \\
\text { organization today and its future. }\end{array}$ \\
\hline $\begin{array}{l}\text { Enactive of Sensible } \\
\text { Environments }\end{array}$ & $\begin{array}{l}\text { Propertied 3: The process of adopting and preparing the IR is the interpretation of the environment and } \\
\text { changes to which the company attributes meaning. }\end{array}$ \\
\hline Social & $\begin{array}{l}\text { Propertied 4: The process of adopting and preparing the IR is realized out collective the agents involved in } \\
\text { these processes. }\end{array}$ \\
\hline Ongoing & $\begin{array}{l}\text { Propertied 5: The process of adopting and preparing the IR is a continuous process of analyzing the } \\
\text { creation of value, capital and integration of information. }\end{array}$ \\
\hline $\begin{array}{l}\text { Focused on And by } \\
\text { Extracted Cues }\end{array}$ & $\begin{array}{l}\text { Propertied 6: The process of adopting and preparing the IR uses reference points (cues) from which ideas } \\
\text { can be connected in networks of meaning. }\end{array}$ \\
\hline Driven by plausibility & $\begin{array}{l}\text { Propertied 7: The process of adopting and preparing the IR uses guiding principles (such as material, } \\
\text { conciseness, requirements) to evaluate the information included. }\end{array}$ \\
\hline
\end{tabular}

Note. The properties were elaborated according to the literature and, subsequently, adapted during the interpretation of the statements (content analysis stage - section 3) so that they could guide and build the analysis of the result of this study (section 4). In this study, we did not intend to test the properties, but to guide the analysis of the interviews in the context of the Integrated Report.

Source: Adapted from Weick (1995, p. 17-60).

\section{Appendice B - Script for semi-structured interviews}

\begin{tabular}{|c|c|}
\hline Question & Possible element of the weick model (1995) \\
\hline $\begin{array}{l}\text { what is your job role in the organization? What are your responsibilities and } \\
\text { tasks? And who do you report to? }\end{array}$ & Identity construction; Social. \\
\hline $\begin{array}{l}\text { Please, do a general review of your organization's economic, social and } \\
\text { environmental context. }\end{array}$ & $\begin{array}{l}\text { Identity construction; Enactive of sensible } \\
\text { environments. }\end{array}$ \\
\hline $\begin{array}{l}\text { What does the term Integrated Reporting significant to you and your } \\
\text { company? }\end{array}$ & $\begin{array}{l}\text { Identity construction; Enactive of sensible } \\
\text { environments; Focused on and by extracted cues. }\end{array}$ \\
\hline $\begin{array}{l}\text { How was the Integrated Reporting proposal inserted in the context of your } \\
\text { organization? }\end{array}$ & $\begin{array}{l}\text { Identity construction; Retrospective experience; } \\
\text { Focused on and by extracted cues. }\end{array}$ \\
\hline $\begin{array}{l}\text { How does Integrated Reporting differ from sustainability and financial } \\
\text { reporting? }\end{array}$ & $\begin{array}{l}\text { Pautado na plausibilidade; Enactive of sensible } \\
\text { environments. }\end{array}$ \\
\hline What are the benefits and challenges of Integrated Reporting? & Enactive of sensible environments; Ongoing. \\
\hline $\begin{array}{l}\text { Discuss your organization's transition to Integrated Reporting practice } \\
\text { (compared to the model in practice previously), explaining how Integrated } \\
\text { Reporting was implemented in your organization. }\end{array}$ & Retrospective experience. \\
\hline $\begin{array}{l}\text { Who are the main actors (individuals / sectors) involved in the Integrated } \\
\text { Reporting process in your organization? Did these employees start to dedicate } \\
\text { only to the Integrated Report process or did they accumulate tasks? Was it } \\
\text { necessary the assistance of agents external to the organization, in the consulting } \\
\text { function? }\end{array}$ & Identity construction. \\
\hline $\begin{array}{l}\text { Identify the key success factors in your organization in the transition to } \\
\text { Integrated Reporting. }\end{array}$ & Enactive of sensible environments. \\
\hline $\begin{array}{l}\text { Why is the organization committing to Integrated Reporting? What lessons } \\
\text { can other organizations learn from their Integrated Reporting experience? }\end{array}$ & Enactive of sensible environments. \\
\hline What are your organization visions for the future of Integrated Reporting? & Driven in plausibility. \\
\hline How was the concept of creating value created? What is this concept? & Identity construction; Focused on and by extracted cues. \\
\hline How were capitals identified? What are the difficulties? & Social \\
\hline $\begin{array}{l}\text { How was the process (protocol for) of information connectivity defined? What } \\
\text { parts of the organization were involved? }\end{array}$ & Identity construction; Social. \\
\hline
\end{tabular}


Supporting Agencies: Coordination for the Improvement of Higher Education Personnel (CAPES)

\section{Authors:}

1. Simone Leticia Raimundini Sanches, PhD in Management, Business School/Federal University of Rio Grande do Sul (EA/UFRGS), Porto Alegre, Brazil. E-mail: slraimundini@uem.br

ORCID

(iD)0000-0002-7363-2573

2. Kelli Juliane Favato, Master in Accounting, State University of Maringá (UEM), Maringá, Brazil.

E-mail: kelli.favato@gmail.com

ORCID

(iD 0000-0001-8360-8318

3. Evelise Slewinski, Master in Accounting, State University of Maringá (UEM), Maringá, Brazil.

E-mail: evelise.sle@gmail.com

\section{ORCID}

(iD 0000-0003-0876-4905

4. Marguit Neumann, PhD Development Economics, Federal University of Rio Grande do Sul (UFRGS), Porto Alegre, Brazil.

E-mail: marguitn26@gmail.com

ORCID

(DD0000-0003-1246-3769

\section{Contribution of each author}

\begin{tabular}{|c|c|c|c|c|}
\hline Contribution & $\begin{array}{l}\text { Simone } \\
\text { Sanches }\end{array}$ & $\begin{array}{c}\text { Kelli } \\
\text { Favato }\end{array}$ & $\begin{array}{c}\text { Evelise } \\
\text { Slewinski }\end{array}$ & $\begin{array}{l}\text { Marguit } \\
\text { Neumann }\end{array}$ \\
\hline 1. Definition of research problem & $\sqrt{ }$ & $\sqrt{ }$ & $\sqrt{ }$ & $\sqrt{ }$ \\
\hline 2. Development of hypotheses or research questions (empirical studies) & $\sqrt{ }$ & $\sqrt{ }$ & $\sqrt{ }$ & $\sqrt{ }$ \\
\hline \multicolumn{5}{|l|}{ 3. Development of theoretical propositions ( theoretical Work ) } \\
\hline 4. Theoretical foundation/ Literature review & $\sqrt{ }$ & $\sqrt{ }$ & $\sqrt{ }$ & \\
\hline 5. Definition of methodological procedures & $\sqrt{ }$ & & $\sqrt{ }$ & \\
\hline 6. Data collection & $\sqrt{ }$ & $\sqrt{ }$ & $\sqrt{ }$ & \\
\hline \multicolumn{5}{|l|}{ 7. Statistical analysis } \\
\hline 8. Analysis and interpretation of data & $\sqrt{ }$ & $\sqrt{ }$ & & \\
\hline 9. Critical revision of the manuscript & $\sqrt{ }$ & $\sqrt{ }$ & & $\sqrt{ }$ \\
\hline 10. Manuscript Writing & $\sqrt{ }$ & $\sqrt{ }$ & & \\
\hline 11. Other (please specify which) & & & & \\
\hline
\end{tabular}

